\title{
KUALITAS ANTENATAL CARE DENGAN KEPUASAN IBU HAMIL
}

\section{QUALITY OF ANTENATAL CARE WITH PREGNANT SATISFACTION}

\author{
Azizatul Hamidiyah', Nur Hidayati \\ Prodi DIII Kebidanan, Fakultas Ilmu Kesehatan, Universitas Ibrahimy \\ ${ }^{1}$ Email: azizatulhamidiyah@ibrahimy.ac.id
}

\begin{abstract}
ABSTRAK
Salah satu upaya peningkatan derajat kesehatan ibu hamil adalah dengan memastikan ibu hamil rutin melakukan pemeriksaan kehamilan. Motivasi ibu hamil untuk melakukan pemeriksaan kehamilan secara rutin perlu diimbangi dengan pelayanan Antenatal Care (ANC) yang berkualitas agar ibu hamil puas dan termotivasi untuk melakukan kunjungan berikutnya. Hasil laporan Puskesmas Banyuputih selama tiga tahun terakhir menunjukkan kunjungan K4 mengalami penurunan. Khususnya pada tahun 2016 ke 2017 yaitu dari $106 \%$ menjadi $68 \%$. Sehingga penting dilakukan penelitian tentang kualitas pelayanan ANC dengan kepuasan.Tujuan penelitian ini adalah untuk mengetahui hubungan kualitas pelayanan $A N C$ dengan kepuasan ibu hamil di Puskesmas Banyuputih Kabupaten Situbondo Tahun 2018. Metode penelitian ini adalah kuantitatif dengan desain crosssectional. Populasi dalam penelitian ini adalah ibu hamil yang telah melakukan pelayanan ANC di Puskesmas Banyuputih selama tahun 2018. Sampel dalam penelitian ini sebanyak 61 orang. Pengumpulan data dilakukan menggunakan data primer dan sekunder. Instrumen penelitian ini adalah kuesioner menggunakan skala likert. Analisi data dilakukan menggunakan uji chi square. Hasil penelitian menunjukkan ada hubungan antara kualitas pelayanan yaitu dimensi Reliability (0,000), Responsiveness (0,007), asssurance (0,016), Emphaty (0,001) dan Tangible $(0,016)$ dengan kepuasan pasien.
\end{abstract}

Kata kunci : Kualitas, Antenatal Care, Kepuasan

\begin{abstract}
One of the efforts to improve health of pregnant women is ensure that pregnant women routinely carry out antenatal care. The motivation of pregnant women to carry out routine pregnancy checks needs to be balanced with quality Antenatal Care (ANC) so that pregnant women are satisfied and motivated to make the next visit. The results of Banyuputih Public Health Center reported for the past three years showed that K4 visits have decreased. Especially in 2016 to 2017, from 106\% to 68\%. So it is important to do research quality of $A N C$ with satisfaction. The purpose of this study was to determine the relationship between the quality of ANC services and the satisfaction of pregnant women in Banyuputih Public Health Center in Situbondo District in 2018. This research method was quantitative with cross sectional design. The population in this study were pregnant women who had performed ANC services at Banyuputih Health Center during 2018. The sample in this study were 61 people. Data collection was done using primary and secondary data. This research instrument was a questionnaire using a Likert scale. Data analysis was performed using chi square test. The results showed that there was a relationship between service quality, dimensions of Reliability (0,000), Responsiveness (0,007), Assurance (0,016), Emphaty (0,001) and Tangible $(0,016)$ with patient satisfaction
\end{abstract}

Keywords : Quality, Antenatal Care, Satisfaction

\section{PENDAHULUAN}

Pelayanan Poli Kesehatan Ibu

dan Anak (KIA) di Puskesmas memiliki peranan yang penting dalam meningkatkan kesehatan ibu dan anak, salah satunya memberikan pelayanan 
Antenatal Care (ANC) Terpadu $10 \mathrm{~T}$ bagi ibu selama hamil. $A N C$ adalah pelayanan kesehatan yang terencana berupa observasi, edukasi dan penanganan medik pada ibu hamil diberikan oleh tenaga kesehatan professional (tenaga kesehatan) dengan frekuensi kunjungan paling sedikit empat kali dilaksanakan sesuai standar pelayanan $A N C$ yang telah ditetapkan dalam standar pelayanan kebidanan. Sehingga, kualitas pelayanan $A N C$ memiliki peran yang cukup besar dalam mencegah kematian ibu dan anak (Adam, et al., 2015).

Berdasarkan Profil Kesehatan Kabupaten Situbondo Tahun 2016 menunjukkan bahwa kematian ibu di Kabupaten Situbondo masih tinggi dan belum mencapai target yang ditentukan sebagaimana Gambar 1.

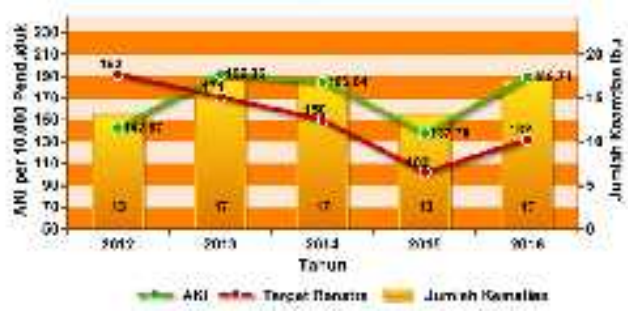

Gambar 1 Trend Kematian Ibu Kabupaten Situbondo

Puskesmas

Banyuputih

merupakan Puskesmas yang selalu memiliki kasus kematian Ibu setiap tahunnya. Berdasarkan studi pendahuluan yang dilakukan di
Puskesmas Banyuputih didapatkan hasil K1 dan K4 sebagaimana Tabel 1.

Tabel 1 Data K1 dan K4 Ibu Hamil di Puskesmas Banyuputih

\begin{tabular}{ccccccc}
\hline \multirow{2}{*}{$\mathbf{K}$} & \multicolumn{2}{c}{$\mathbf{2 0 1 5}$} & \multicolumn{2}{c}{$\mathbf{2 0 1 6}$} & \multicolumn{2}{c}{$\mathbf{2 0 1 7}$} \\
& $\mathbf{N}$ & $\mathbf{\%}$ & $\mathbf{N}$ & $\mathbf{\%}$ & $\mathbf{N}$ & $\mathbf{\%}$ \\
\hline K1 & 924 & 101 & 766 & 104 & 772 & 87 \\
K4 & 882 & 96.5 & 783 & 106 & 602 & 68 \\
\hline \multicolumn{4}{c}{ Berdasarkan Tabel 1 menunjukkan }
\end{tabular}

bahwa terjadi penurunan dari kunjungan K1 dan K4. Dan pada cakupan K4 di Puskesmas Banyuputih selama tiga tahun terakhir mengalami penurunan, tahun 2016 ke 2017 terjadi penurunan yang cukup dastis dari $106 \%$ menjadi $68 \%$. Oleh karena itu, penting dilakukan penelitian tentang hubungan kualitas pelayanan $A N C$ dengan kepuasan ibu hamil di Puskesmas Banyuputih untuk mengukur kinerja pelayanan $A N C$ Puskesmas dari hasil penilaian kualitas pelayanan $A N C$ dan tingkat kepuasan ibu hamil terhadap pelayanan yang telah diberikan.

Tujuan penelitian ini adalah untuk mengetahui hubungan kualitas pelayanan $A N C$ dengan kepuasan ibu hamil di Puskesmas Banyuputih Kabupaten Situbondo Tahun 2018.

\section{METODE PENELITIAN}

Penelitian ini merupakan penelitian kuantitatif dengan desain penelitian cross sectional. Populasi penelitian ini adalah seluruh ibu hamil 
yang telah melakukan pemeriksaan $A N C$ di Puskesmas Banyuputih pada tahun 2018. Sampel pada penelitian ini adalah 61 ibu hamil yang telah mendapatkan pelayanan ANC di Poli KIA Puskesmas Banyuputih mulai dari registrasi, pelayanan $10 \mathrm{~T}$, Obat hingga kasir. Sampel dalam penelitian ini sebanyak 61 responden dengan kriteria inklusi dan ekslusi.

Data yang dikumpulkan dalam penelitian ini berupa data primer dan data sekunder. Instrumen yang digunakan dalam penelitian ini adalah kuesioner terstruktur menggunakan skala likert. Analisis data dilakukan menggunakan uji statistik chi square.

\section{HASIL DAN PEMBAHASAN}

Puskesmas Banyuputih merupakan Puskesmas yang terletak di Kecamatan Banyuputih di Kabupaten Situbondo yang terletak di bagian timur, dan berbatasan langsung dengan Kabupaten Banyuwangi. Semua desa di kecamatan Banyuputih berbatasan langsung dengan garis pantai, atau yang biasa disebut desa pantai.Jarak masingmasing desa ke ibu kota kecamatan bervariasi antara $0-26 \mathrm{~km}$.

Karakteristik responden dalam penelitian ini sebagaimana Tabel 2 .
Tabel 2 Karakteristik Responden

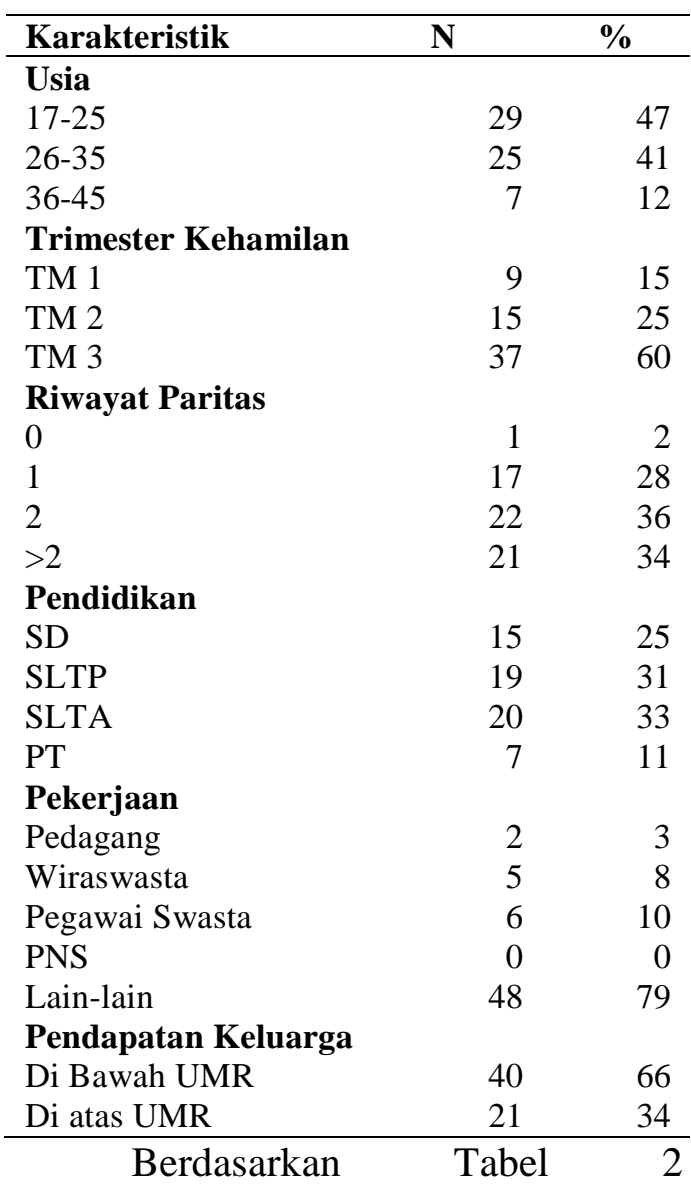

menunjukkan bahwa mayoritas responden berusia 17-25 tahun sebesar $47 \%$, sebagian besar responden berada pada trimester akhir kehamilan sebesar $60 \%$, Sebagian besar responden memiliki riwayat paritas 2 sebanyak $36 \%$, pendidikan mayoritas lulusan SLTA sebesar 33\%, pekerjaaan sebagian bear Ibu Rumah Tangga dan pendapatan keluarga di bawah Upah Minimum Rat-rata (UMR) sebesar 66\%. Hasil analisis univariat gambaran kualitas pelayanan ANC dan kepuasan ibu hamil sebagaimana Tabel $3 \& 4$. 
Tabel 3 Gambaran Kualitas Pelayanan ANC di Puskesmas Banyuputih Tahun 2018

\begin{tabular}{lll}
\hline Kualitas ANC & N & \% \\
\hline Reliability & 32 & 52 \\
Baik & 29 & 48 \\
Tidak Baik & & \\
$\begin{array}{l}\text { Responsiveness } \\
\text { Baik }\end{array}$ & 31 & 51 \\
Tidak Baik & 30 & 49 \\
Assurance & & \\
Baik & 36 & 59 \\
Tidak Baik & 25 & 41 \\
Emphaty & & \\
Baik & 36 & 59 \\
Tidak Baik & 25 & 41 \\
Tangible & & \\
Baik & 34 & 56 \\
Tidak Baik & 27 & 44 \\
\hline
\end{tabular}

Tabel 4 Gambaran Kepuasan Ibu Hamil Puskesmas Banyuputih Tahun 2018

\begin{tabular}{lrr}
\hline Kepuasan & N & \% \\
\hline Puas & 32 & 52 \\
Tidak Puas & 29 & 48 \\
\hline
\end{tabular}

Secara keseluruhan gambaran kualitas pelayanan ANC dalam kategori baik yaitu Reliability 52\%, Responsiveness 51\%, Assurance 59\%, Emphaty 59\% dan Tangibles 56\%. Dan sebagian besar ibu hamil puas terhadap pelayanan ANC di Puskesmas Banyuputih sebesar 52\%. Akan tetapi baik hasil kualitas dan kepuasan walaupun dominan dalam kategori baik dan puas, secara kuantitatif masih terbilang kecil.

Hasil analisis bivariat sebagaiman dalam tabel 5.

Tabel 5 Hubungan Kualitas Pelayanan ANC dengan Kepuasan Ibu Hamil Puskesmas Banyuputih Tahun 2018

\begin{tabular}{|c|c|c|c|c|c|c|c|}
\hline \multirow{3}{*}{ Variabel } & \multicolumn{4}{|c|}{ Kepuasan Ibu Hamil } & \multirow{2}{*}{\multicolumn{2}{|c|}{ Total }} & \multirow{3}{*}{ Pvalue } \\
\hline & \multicolumn{2}{|c|}{ Puas } & \multicolumn{2}{|c|}{ Tidak Puas } & & & \\
\hline & $\mathbf{N}$ & $\%$ & $\mathbf{N}$ & $\%$ & \multirow{2}{*}{$\mathbf{N}$} & \multirow[t]{2}{*}{$\%$} & \\
\hline \multicolumn{6}{|l|}{ Reliability } & & \\
\hline Baik & 27 & 84 & 5 & 16 & 32 & 100 & 0,000 \\
\hline Tidak Baik & 5 & 17 & 24 & 83 & 29 & 100 & \\
\hline \multicolumn{8}{|l|}{ Responsiveness } \\
\hline Baik & 22 & 71 & 29 & 29 & 31 & 100 & 0,007 \\
\hline Tidak Baik & 10 & 33 & 20 & 67 & 30 & 100 & \\
\hline \multicolumn{8}{|l|}{ Assurance } \\
\hline Baik & 24 & 67 & 12 & 33 & 36 & 100 & 0,016 \\
\hline Tidak Baik & 8 & 32 & 17 & 68 & 25 & 100 & \\
\hline \multicolumn{8}{|l|}{ Emphaty } \\
\hline Baik & 26 & 72 & 10 & 28 & 36 & 100 & 0,001 \\
\hline Tidak Baik & 6 & 24 & 19 & 76 & 25 & 100 & \\
\hline \multicolumn{8}{|l|}{ Tangible } \\
\hline Baik & 23 & 68 & 11 & 32 & 34 & 100 & 0,016 \\
\hline Tidak Baik & 9 & 33 & 18 & 67 & 27 & 100 & \\
\hline
\end{tabular}

Berdasarkan tabel silang dan uji chi square menunjukkan bahwa responden yang mengatakan realiability baik dan puas terhadap pelayanan ANC sebesar $84 \%$, dan responden yang 
mengatakan Reliability tidak baik dan tidak puas sebesar $83 \%$.

Reliability berkaitan erat dengan kemampuan Puskesmas dalam memberikan pelayanan yang segera, tepat waktu dan akurat sesuai dengan yang dijanjikan tanpa melakukan kesalahan. Reliability dalam penelitian ini ditunjukkan dengan keberadaan petugas mulai dari registrasi sampai akhir pelayanan di masing-masing pos, prosedur pelayanan yang tidak berbelitbelit.

Hasil uji statistik menggunakan chi square menunjukkan nilai Pvalue 0,000. Hal ini menunjukkan adanya hubungan antara kualitas pelayanan ANC dengan kepuasan ibu hamil. Hasil penelitian ini sesuai sebagaimana penelitian yang dilakukan oleh Syamsudin dan Hartiningsih (2012), Mursyida, dkk (2012) bahwa ada hubungan antara Reliability pelayanan ANC dengan kepuasan ibu hamil.

Responsiveness adalah respon atau kesiapan petugas dalam membantu pasien dengan cepat dan tanggap. Responsiveness dalam penelitian ini diantaranya kecepatan pasien mendapatkan pelayanan di masingmasing pos dari register hingga poli. Respon bidan dalam menanggapi keluhan pasien dan kecepatan serta ketepatan dalam memberikan informasi. Hasil penelitian menunjukkan responden yang mengatakan responsiveness dalam kategori baik dan puas sebanyak $71 \%$. Hasil uji statistik menunjukkan Pvalue 0,007. Hal ini menunjukkan bahwa ada hubungan antara Responsiveness dengan kepuasaan pasien. Sehingga perlu dilakukan upaya peningkatan pada aspek Responsiveness pelayanan ANC. Hasil penelitian ini linier seperti penelitian yang dilakukan oleh Syamsudin dan Hartiningsih (2012), Mursyida, dkk (2012).

Dalam pelayanan ANC Assurance merupakan kemampuan para petugas kesehatan yang membuat pasien percaya akan melakukan pemeriksaan kesehatan di tempat tersebut. Assurance dalam penelitian ini terdiri dari kamampuan dan kecakapan bidan dalam memberikan pelayanan kepada ibu hamil, tidak ada perbedaan antar pasien, pemeriksaan dilakukan dengan aman dan sopan.

Hasil penelitian menunjukkan bahwa responden yang mengkategorikan Assurance dalam kategori baik dan puas sebanyak $67 \%$. Hasil uji statistik didapatkan nilai 
Pvalue sebesar 0, 016 artinya ada hubungan antara simensi kualitas pelayanan asssurance dengan kepuasan pasien.

Emphaty adalah upaya perhatian individual yang diberikan petugas kesehatan kepada pasien. Wujud Emphaty dalam pelayanan ANC dalam penelitian ini terdiri dari keramahan petugas puskesmas dari register hingga poli. Kepekaan petugas kesehatan terhadap apa yang dirasakan oleh pasien.

Hasil penelitian menunjukkan Pvalue 0,001 artinya ada hubungan kualitas pelayanan dengan kepuasan ibu hami. Sehingga perlu peningkatan kualitas pelayanan ANC dimensi Emphaty, utamanya pada poin yang memiliki kesenjangan tidak kecil yaitu bentuk perhatian bidan dalam memberikan pelayanan dan kepekaan bidan terhadap apa yang dialami pasien.

Sedangkan Tangible merupakan dimensi kualitas pelayanan yang dapat dirasakan langsung oleh para penggunanya melalui perlengkapan yang memadai.

Hasil penelitian menunjukkan ibu hamil yang mengatakan Tangible dalam kategori baik dan puas sebanyak 68\%. Hasil uji statistik menunjukkan Pvalue 0,016 artinya ada hubungan dimensi Tangible dengan kepuasan pasien. Sehingga dibutuhkan upaya peningkatan kualitas pelayanan ANC untuk membuat pasien puas.

Secara keseluruhan hasil penelitian ini sesuai sebagaimana menurut Parasuraman dalam Hamidiyah (2013) dan sesuai sebagaimana hasil penelitiaan Syamsudin dan Hartiningsih (2012), Mursyida, dkk (2012), Rahayu, dkk (2015) bahwa kualitas berhubungan dengan kepuasan pasien, dimana apabila pasien puas maka akan melakukan kunjungan ulang.

\section{SIMPULAN DAN SARAN}

Simpulan penelitian ini yaitu ada hubungan kualitas pelayanan ANC yaitu dimensi Reliability (Pvalue 0,000), Responsiveness (Pvalue 0,007), Assurance (Pvalue 0,016), Emphaty (Pvalue 0,001) dan Tangible (Pvalue 0,016) dengan kepuasan ibu hamil.

Saran dalam penelitian ini yaitu Puskesmas Banyuputih agar meningkatkan kualitas pelayanan ANC baik pada dimensi Reliability, Responsiveness, Assurance, Emphaty dan Tangible sehingga cakupan K1 dan K4 dapat tercapai sesuai target ibu hamil dapat meningkat derajat kesehatannya. 


\section{UCAPAN TERIMA KASIH}

Ucapan terimakasih penulis sampaikan untuk pihak-pihak yang telah membantu dalam mensukseskan penelitian, khususnya untuk DRPM Kemenristekdikti RI yang telah memberi kesempatan dan mendanai Penelitian Dosen Pemula (PDP) ini.

\section{DAFTAR PUSTAKA}

Adam, M., Wati, Y. R. \& Budiman, 2015. Hubungan Karakteristik Antenatal Care (ANC) dengan Kematian Ibu. Bandung, Prosiding Pendidikan Dokter UNISBA.

Amran, Y. 2012. Pengolahan Data dan Analisis Data Statistik di Bidang Kesehatan. Ciputat: FKIK UIN Jakarta

Ariawan, I. 1998. Besar dan Metode Sampel pada Penelitian Kesehatan.Depok: FKMUI

Dinas Kesehatan Kabupaten Situbondo. 2015. Profil Kesehatan Kabupaten Situbondo. Situbondo: Dinas Kesehatan Kabupaten Situbondo

Hamidiyah, A. 2013. Hubungan Persepsi Pasien Tentang Kualitas Pelayanan Dengan Minat Kunjungan Ulang Di Klinik Umum Rumah Sakit Bhinneka Bakti Husada Tangerang Selatan i 125 2013. Jakarta: UIN Syarif Hidayatullah Jakarta

Hidayat, A.A. A. 2007. Metode Penelitian dan Keperawatan dan Teknik Analisis Data. Jakarta: Salemba Medika

Jasfar, F. 2009. Manajemen Jasa. Bogor: Ghalia Indonesia

Muninjaya, A.A.G. 2011. Manajemen Mutu Pelayanan Kesehatan. Jakarta: EGC

Mursyida, R.F., dkk, 2012. Kepuasan Ibu Hamil dan Persepsi Kualitas Pelayanan Antenatal Care di Puskesmas Tanjung Kabupaten Sampang.

Notoatmodjo, S. 2010. Metodologi Penelitian Kesehatan. Jakarat: PT.Rineka Cipta

Rustiyanto, E. 2010. Statistik Rumah Sakit untuk Pengambilan Keputusan. Jakarta: Graha Ilmu

Syamsudin, A., Hartiningsih, S.S. 2012. Hubungan Kualitas Pelayanan Antenatal Care (ANC) dengan Kepuasan Pasien dalam Kegiatan Gempungan di Wilayah Kerja Puskesmas Sukasari Kabupaten Purwakarta Tahun 2011. Prosiding Seminar Nasional Kesehatan. Purwokerto: UNSOED

Tjiptono, F. 2009. Service Marketting: Esensi dan Aplikasi. Jogjakarta: Marknesis

Trimurthy, I. 2008. Analisis Hubungan Persepsi Pasien tentang Mutu Pelayanan dengan Minat Pemanfaatan Ulang Pelayanan Rawat Jalan Puskesmas Pandanaran Kota Semarang. Tesis.Semarang: UNDIP 